\title{
ALGUMAS CONCEPÇÕES DE ALUNOS DO ENSINO MÉDIO A RESPEITO DAS PROTEÍNAS
}

\section{High School students' conceptions about proteins}

\author{
Julio Cesar Queiroz de Carvalho ${ }^{1}$. Sheila Gonçalves do Couto ${ }^{2}$. \\ Nelma Regina Segnini Bossolan ${ }^{3}$
}

Resumo: O conceito de proteína e sua síntese são importantes para a compreensão de processos em biotecnologia, por exemplo, a produção de novos fármacos, área em avanço nas últimas décadas. Assim, o objetivo desse trabalho foi verificar, dentre alunos do Ensino Médio, quais tipos de concepções eles têm ou trazem sobre proteína e síntese proteica, e que tipo de influência pode ter contribuído para a formulação de tais concepções, através de um questionário diagnóstico, composto por questões abertas, aplicado a 133 alunos de uma escola pública e de uma particular. Os resultados analisados basearam-se em categorização de respostas. Concluímos que, mesmo os alunos já tendo estudado assuntos relativos a proteínas, ainda carregavam traços de concepções alternativas, o que forneceu informações valiosas sobre possíveis falhas no processo de aprendizagem. Assim, para que haja uma "ressignificação" desses conceitos, é necessário que as discussões desse tema sejam ampliadas, vinculando-os aos conteúdos correlatos previamente trabalhados.

Palavras-chave: Proteína. Ensino de biologia. Ensino Médio. Ensino-aprendizagem.

Abstract: The concept of protein and its synthesis is important in order to understand biotechnology processes, such as the production of new drugs, an area in great progress. Thus, this study aimed to verify, among high school students, what kinds of ideas these students have about protein and protein synthesis, and what kind of influence contributed to the formulation of such concepts, through a diagnostic questionnaire with open questions, that was administered to 133 students from a public school and a private school. The results analyzed were based on the categorization of responses. We conclude that although the students having already studied the issues related to proteins, they still carried traces of alternative conceptions, which provided valuable information about possible failures in the learning process. Thus, to have a "reinterpretation" of these concepts, it is necessary that the discussions of this topic are expanded, linking them to related content which has previously been researched.

Keywords: Protein. Biology teaching. High school. Teaching-learning.

\footnotetext{
${ }^{1}$ Programa de Pós-graduação Interunidades em Ensino de Ciências, Universidade de São Paulo (USP). Caixa postal 66318. São Paulo, SP, Brasil. 05.314-970. jcqcarvalho@usp.br

${ }^{2}$ Instituto de Física, Universidade Federal de Goiás (UFG). Goiânia, GO, Brasil.

${ }^{3}$ Instituto de Física de São Carlos, Universidade de São Paulo (USP). São Carlos, SP, Brasil.
} 


\section{Introdução}

Nas últimas décadas, os avanços na área de Biologia Molecular e Biotecnologia tiveram seu foco direcionado não somente para o estudo do genoma, mas passaram a ter um olhar mais cuidadoso para o produto gênico, no caso, as proteínas. Em 2001, em entrevista à revista Ciência Hoje, o americano Walter Gilbert - o mesmo que, em 1980, juntamente com o britânico Frederick Sanger e o americano Paul Berg, ganhou o prêmio Nobel de Química pela criação de um método para a determinação da sequência de nucleotídeos que compõe o DNA - apontou o rumo da pesquisa biológica para aquela e as próximas décadas. Segundo Gilbert (2001), a genômica estrutural e a proteômica seriam os campos dominantes, tendo a bioinformática um papel fundamental.

É lógico pensarmos que o avanço da ciência só foi e é possível aliado ao avanço tecnológico, e, nessa área, não está sendo diferente. Hoje em dia, os cientistas dispõem de uma série de ferramentas tanto no campo da Biologia Molecular, na obtenção e preparação das amostras, quanto no campo da Física, com técnicas que permitem desde a determinação estrutural de uma proteína, sua caracterização, até o estudo de sua dinâmica.

Sabemos que a área de Biologia Molecular e Biotecnologia, assim como a Ciência de uma forma geral, encontra-se em constante avanço, fazendo com que educadores da área de Ciências se preocupem em aproximar a Ciência e a Tecnologia, presentes no cotidiano dos alunos, do universo de sala de aula. Os parâmetros curriculares nacionais (PCN) para o Ensino Médio, na parte destinada a Ciências da natureza, matemática e suas tecnologias, pontuam a relação dessa temática no contexto Ciência, Tecnologia e Sociedade (CTS):

O desenvolvimento da Genética e da Biologia Molecular, das tecnologias de manipulação do DNA e da clonagem traz à tona aspectos éticos envolvidos na produção e aplicação do conhecimento científico e tecnológico, chamando à reflexão sobre as relações entre a ciência, a tecnologia e a sociedade. Conhecer a estrutura molecular da vida, os mecanismos de perpetuação, diferenciação das espécies e diversificação intraespecífica, a importância da biodiversidade para a vida no planeta são alguns dos elementos essenciais para um posicionamento criterioso relativo ao conjunto das construções e intervenções humanas no mundo contemporâneo. (BRASIL, 1999, p. 219)

Com isso, percebe-se a necessidade de um ensino que acompanhe essa evolução, esses avanços científicos e tecnológicos, de forma que a sala de aula passe a abrir espaço para discussões que vão além do currículo escolar, além do ensino formal, sistematizado, preocupado não somente com a formação de conceitos por parte dos alunos, mas em oferecer subsídios para que os mesmos tenham autonomia e possam participar mais ativamente do mundo em que vivem, um ensino voltado para a inclusão dos alunos na sociedade.

A proposta dos $\mathrm{PCN}+$ é de um ensino por competências, em que se propõe a organização do conhecimento 
[...] a partir não da lógica que estrutura a ciência, mas de situações de aprendizagem que tenham sentido para o aluno, que lhe permitam adquirir um instrumental para agir em diferentes contextos e, principalmente, em situações inéditas de vida. (BRASIL, 2002, p. 42)

Dessa forma, a sugestão dos PCN+ é a de um currículo de Biologia que não siga a sequência programática da maneira tradicional, mas organizado de forma que os conteúdos a serem ministrados aos alunos, durante o Ensino Médio, estejam agrupados em temas estruturadores. Será destacado o tema estruturador "Identidade dos seres vivos" por compreender o estudo das proteínas e da síntese proteica, tema central de nossa investigação, e que é subdividido em quatro unidades temáticas que propõem competências a serem desenvolvidas. Com relação ao tema proteínas, a unidade "A organização celular da vida" propõe a representação de diferentes tipos de células a partir da utilização de instrumentos ópticos, observação de fotos e representações e pesquisa em textos científicos. A unidade "As funções vitais básicas" propõe a análise de imagens e representações relacionadas aos diferentes tipos de transporte através da membrana. Com relação ao tema síntese proteica, a unidade "DNA: a receita da vida e seu código" propõe: (a) localizar o material hereditário em células de diferentes organismos, a partir de fotos e representações esquemáticas; (b) estabelecer relação entre DNA, código genético, fabricação de proteínas e determinação das características dos organismos; (c) analisar esquemas que relacionam os diferentes tipos de ácidos nucleicos, as organelas celulares e o mecanismo de síntese de proteínas específicas.

Ao se tratar do ensino e aprendizagem de conceitos, Vygotsky (1991) e seus colaboradores concluem que, embora o processo de formação de conceitos comece na infância, o desenvolvimento das bases psicológicas que vão oferecer suporte para o processo de formação dos conceitos verdadeiros só amadurece na fase da adolescência.

A formação de conceitos, portanto, é um processo que acompanha as etapas de amadurecimento desde a infância, passando pela adolescência e atingindo a fase adulta, aumentando seu grau de complexidade, estimulado não somente por interações com o meio social, mas, sobretudo, pelo domínio da linguagem, dos signos. Devemos, portanto, considerar, segundo Vygotsky (1991), a formação de conceitos como parte do desenvolvimento sociocultural por que passa o adolescente, influenciando seu modo de pensar e agir. Nesse sentido, Vygotsky (1991) afirma que a apropriação e articulação da linguagem como meio da formação de conceitos seja a causa da imediata transformação sofrida pelo processo intelectual no limiar da adolescência.

Dessa forma, educadores que seguem a linha construtivista têm destacado a importância de se dominarem os conhecimentos prévios dos alunos antes de introduzir qualquer nova informação, visto que eles servem de alicerce para o planejamento de estratégias que possam auxiliar os alunos a resolverem os conflitos cognitivos daí gerados. Para a resolução desses conflitos cognitivos, a literatura da área propõe alguns modelos, dentre os quais destacamos o de mudança de perfis conceituais, proposto por Mortimer (1995). Esse modelo propõe não uma substituição de uma concepção por outra, uma ruptura, e, sim, a tomada de consciência de cada uma delas e dos argumentos que justificam o uso de uma ou de outra em determinados contextos. 
A estes conhecimentos conceituais prévios a partir dos quais os alunos constroem o conhecimento dá-se o nome de concepções alternativas (GARCIA-MILÀ, 2004).

Pozo (1987 apud GARCIA-MILÀ, 2004, p. 364), atribui algumas características às concepções alternativas:

\begin{abstract}
- São construções pessoais dos alunos originadas em sua interação cotidiana com o mundo, forma-se de maneira espontânea e habitualmente preexistem ao ensino;

- Apresentam incoerência científica, embora não cotidiana, já que muitas vezes antecipam fenômenos isolados observados pelo aluno em seu ambiente próximo ao transcurso das atividades cotidianas;

- São estáveis e apresentam resistência à mudança, já que os alunos não as modificam apesar de esforços do professor para mudá-las;

- Foram identificadas em crianças, adolescentes e adultos, inclusive em universitários em sua área de especificidade;

- Mantém uma certa correspondência com as ideias expressadas por cientistas em épocas históricas menos evoluídas cientificamente;

- Têm um caráter implícito se comparadas aos conceitos explícitos da ciência, isto é, são difíceis de formular explicitamente e manifestam-se muitas vezes mediantes atividades empíricas sem que os alunos consigam verbalizá-las.
\end{abstract}

Para Pozo et al. (1991 apud POZO, 1998), essas concepções alternativas podem ter três origens: sensorial, adquirida a partir de informações recebidas através dos sentidos, importantes para a interação com o mundo físico; cultural, através das relações dos alunos com o meio social em que estão inseridos, ou seja, a escola, outras pessoas ou através dos meios de comunicação, e, ao contrário das sensoriais, são induzidas; e escolar, ou concepção analógica. Isso se deve ao fato de o aluno, ao se deparar com conhecimentos específicos, sentir a necessidade da formulação de analogias, sejam elas formuladas pelos próprios alunos ou induzidas pelo ensino.

A investigação sobre as concepções alternativas colocou em questão a eficácia do ensino por transmissão de conhecimentos previamente elaborados, e contribuiu, de uma forma mais geral, para levantar dúvidas sobre as visões simplistas da aprendizagem e do ensino das ciências, como a ideia de alguns docentes de que ensinar é uma atividade simples, para a qual basta apenas conhecer a matéria e ter alguma experiência (CACHAPUZ et al., 2005).

Zeidler et al. (2002), em uma pesquisa junto a estudantes americanos do Ensino Médio e de cursos de formação de professores, exploraram suas visões a respeito da natureza da ciência e suas argumentações sobre questões sociocientíficas ao se depararem com conceitos que colocavam em cheque suas concepções prévias a respeito de temas polêmicos, como: o uso de animais em pesquisa, alimentos geneticamente modificados, clonagem humana, entre outros. Este estudo revelou que muitos alunos, ao tomarem as suas decisões, optam por ignorar qualquer conhecimento que não apoie as suas crenças prévias, seja ele científico ou a opinião de um colega. Os estudantes tendiam a selecionar a informação que estava mais de acordo com as suas crenças pessoais sobre o tema colocado. Ainda que muitos deles tivessem 
Algumas concepções de alunos do Ensino Médio ...

aceitado os dados científicos oferecidos, depois preferiram não os usar nos pensamentos que seguiram para tomar as suas decisões sobre as questões sociocientíficas propostas.

Acevedo et al. (2005, p. 1) expõem alguns mitos sobre a inserção da Natureza da Ciência no Ensino de Ciências, com destaque para a "crença de que a sua compreensão é um fator chave na hora de tomar melhores decisões cívicas em questões tecno-científicas de interesse social". Os autores indicam, em seu trabalho, que "os motivos para tomar as decisões parecem basear-se mais em outros fatores que se relacionam com o ideológico, o axiológico e o atitudinal, tais como as crenças e os valores culturais, pessoais e sociais" (ACEVEDO et al., 2005, p. 7).

Quando respeitamos as experiências vividas pelos alunos, suas concepções alternativas, e as utilizamos como ponto de partida de discussões, em que o professor compara as diferentes concepções apresentadas pelos alunos e permite ou traz informações contraditórias, ou propõe situações para comprovar todas as concepções, estamos vinculando ciência à sociedade, como preveem Santos e Schnetzler (2000) em uma abordagem CTS.

Nesse sentido, o presente trabalho considerou, na sua fundamentação, a importância de se compreender como se dá à construção do conhecimento por parte dos alunos, por meio de suas experiências pessoais e relações sociais, e de buscar relações entre as concepções prévias dos alunos com os novos conhecimentos ou conhecimento científico. Esse estudo fez parte de uma pesquisa cujo enfoque foi a avaliação do impacto de um recurso didático, o jogo "Sintetizando Proteínas", no processo de ensino e aprendizagem de alunos do Ensino Médio. Esse jogo foi criado pela Coordenadoria de Educação e Difusão do Centro de Biotecnologia Molecular Estrutural (CBME/Cepid/Fapesp) em parceria com o Centro de Divulgação Científica e Cultural da Universidade de São Paulo (CDCC-USP), ambos na cidade de São Carlos, estado de São Paulo.

O jogo ${ }^{4}$ é formado por um tabuleiro com o desenho de um corte de célula animal, com suas estruturas e organelas; por cartas-objetivos, cada uma contendo uma situação-problema relacionada a uma proteína específica que cada jogador terá de sintetizar; e por peças representativas de nucleotídeos, aminoácidos e proteínas, com suas respectivas cartas de compra. O objetivo desse jogo é, de uma forma dinâmica e lúdica, facilitar o entendimento dos processos de transcrição, tradução e síntese de proteínas.

A proposição de um jogo para compreender o processo da síntese proteica na célula tem o objetivo de colaborar na aquisição de competências voltadas para a investigação e compreensão científica e tecnológica, propostas pelos $\mathrm{PCN}+$ para o ensino de Biologia (BRASIL, 2002), uma vez que pode favorecer o reconhecimento, a utilização e a interpretação de um modelo explicativo e representativo de um sistema biológico.

Antes de avaliar esse material enquanto um recurso didático, foi proposto o levantamento das concepções de alunos do segundo ano do Ensino Médio a respeito do tema proteínas, pertencentes a cinco turmas, sendo três de escolas públicas e duas de uma escola privada, todas da cidade de São Carlos, estado de São Paulo. O intuito desse levantamento foi verificar:

\footnotetext{
${ }^{4}$ Adaptado para versão eletrônica. Disponível em: <http://cbme.usp.br/playercbme/interatividade/ jogosintese/sintetizando.html>. Acesso em: 29 ago. 2012.

901 
(a) quais tipos de concepções esses alunos têm ou trazem sobre esses conceitos, e (b) que tipo de influência pode ter contribuído para a formulação de tais concepções. Em um momento posterior dessa pesquisa, partindo desse levantamento e aliado a uma estratégia proposta de aplicação do jogo, foi analisado quanto o jogo facilitou o entendimento e a compreensão desses conceitos.

\section{Metodologia}

O presente trabalho foi realizado com 133 alunos do segundo ano do Ensino Médio (EM) de duas escolas do município de São Carlos, interior de São Paulo, sendo uma delas pública $(\mathrm{PuS}$ ) (duas turmas, totalizando 65 alunos) e uma particular $(\mathrm{PrS})$ (duas turmas, totalizando 68 alunos). A disciplina Biologia foi regularmente oferecida aos alunos do primeiro e segundo anos de ambas as escolas, com a média de três aulas semanais de cinquenta minutos cada. Os temas "proteínas: estrutura e função" e "síntese de proteínas" fizeram parte do currículo formal destes alunos no primeiro ano do EM, dentro do grande tema Biologia Celular, segundo informações dadas pelos professores das escolas e, também, pelos alunos participantes do estudo. Para a disciplina de Biologia, as duas escolas adotavam, de modo regular no EM, livros didáticos de Biologia, como material de apoio ao professor e aos alunos.

O instrumento de pesquisa adotado consistiu de um questionário, intitulado "Questionário Diagnóstico", composto de duas partes, sendo a primeira composta de um cabeçalho, com a apresentação da pesquisa, suas intenções e termo de compromisso dos alunos com relação à mesma, bem como algumas questões pessoais que permitiram traçar o perfil de cada turma com relação a: época escolar em que o tema pesquisado foi estudado, lembrança do tema proposto, acesso a mídias de divulgação científica, grau de interesse por assuntos ligados a ciência, e grau de instrução e profissão dos pais desses alunos. A segunda parte foi composta de seis questões abertas a respeito do tema proteínas, conforme breve descrição das mesmas que ora se apresenta. A questão 1 apresentou, no enunciado, um diálogo ocorrido em um programa de televisão, cujos participantes mencionam que macarrão é proteína e, por isso, "faz bem". Referente a esse diálogo, foram feitas duas perguntas:

1a) Qual sua opinião a respeito da afirmação do "Zulu": Macarrão é proteína!.... Comente sua resposta;

1b) Falando em proteína, o que você entende por PROTEÍNA?

A questão 2, subdividida em três itens, procurou levantar os conhecimentos dos alunos com relação aos alimentos que constituem fonte de proteínas e ao papel destas moléculas como constituintes dos organismos vivos:

2a) Que alimentos, na sua opinião, são ricas fontes de proteínas?;

2b) Nessa lista de alimentos ricos em proteínas também estão incluídos vegetais, como verduras e legumes?

2c) Onde mais podemos encontrar proteínas? Relacione algumas estruturas que constituem seu corpo ou de outros organismos, como algum tipo de tecido ou secreção que seja constituído basicamente por proteínas.

A questão 3 apresentou, em seu enunciado, as propagandas de três produtos industrializados (sabonete, suplemento proteico e xampu), que destacavam a presença de proteínas 
nas suas constituições, e dois textos breves da mídia impressa, um relatando a necessidade de proteína na dieta das crianças e outro informando o desenvolvimento de um novo tomate transgênico que poderia ser usado para fins terapêuticos por conta da presença de proteínas exógenas. Esta questão foi subdividida em três itens:

3a) A grande questão é: por que precisamos tanto de proteínas? Qual é o grande papel que elas exercem nos organismos?;

3b) Qual sua visão crítica com relação às propagandas acima? Você acha que o fato de possuírem proteínas em suas fórmulas vai provocar os efeitos propostos ou usam isso como slogan para vender mais seus produtos? Comente sua resposta;

3c) Com base nas reportagens acima, comente a respeito dos avanços da ciência com relação à Biotecnologia. Você os vê como positivos? Comente sua resposta.

A questão 4 procurou retomar os conhecimentos dos alunos a respeito do processo de digestão no homem, presente no currículo do ciclo 2 do Ensino Fundamental, conforme seu enunciado:

4) Não resta dúvida de que nosso organismo precisa constantemente suprir suas necessidades de proteínas. Mas como você acha que essas proteínas serão absorvidas pelo nosso organismo? Leve em consideração que os alimentos, antes de serem absorvidos, passam pelo processo de digestão.

Com a questão 5, procurou-se levantar os conhecimentos dos alunos em relação ao processo de síntese proteica, apresentando uma situação em que se prepara um bolo a partir de uma receita e se compara essa cozinha a uma célula do corpo e, o bolo, a uma proteína. Partindo desta situação, propuseram-se as perguntas:

5a) O que representa a gaveta onde se encontra o livro de receitas?;

5b) O que representa o livro de receita?;

5c) $\mathrm{O}$ que representa a receita?;

$5 \mathrm{~d}) \mathrm{O}$ que representa os ingredientes?

A questão 6 foi formulada com o objetivo de se levantarem os conhecimentos dos alunos sobre as doenças ou deficiências relacionadas às proteínas, conforme apresentada no enunciado:

6) Você saberia relacionar alguma doença ou deficiência, de que já tenha ouvido falar, cuja causa está relacionada a alguma proteína específica? Não precisa escrever o nome da proteína, somente a doença.

Para a construção das questões, no que se refere ao enunciado e às alternativas (quando foi o caso), levou-se em conta as orientações propostas em Haydt (1994) e Gil (1999). A análise das respostas dadas às questões abertas foi feita segundo Ludke e André (1986), e Bogdan e Biklen (1994), que propõem a distribuição das respostas em categorias.

A aplicação desse questionário em cada turma foi feita na própria escola, nos respectivos períodos de aula, com a presença do professor de Biologia, e constou das seguintes etapas: primeiramente, apresentou-se o projeto e se ressaltou a importância do comprometimento de cada aluno com o mesmo quanto à sinceridade e autenticidade das respostas dadas. Em seguida, foi feita a leitura do questionário com os alunos, procurando sanar possíveis dúvidas que os prejudicassem no entendimento das questões, impossibilitando-os de respondê-las com clareza. 
Cada turma teve um tempo disponível de cem minutos, o que correspondeu a duas aulas de cinquenta min cada, sendo o suficiente para que os alunos respondessem o questionário sem que o tempo fosse um fator limitante.

No presente estudo, serão discutidas as categorias de respostas observadas nas seguintes questões:

1b) Falando em proteína, o que você entende por PROTEÍNA?

2a) Que alimentos, na sua opinião, são ricas fontes de proteínas?

2b) Nessa lista de alimentos ricos em proteínas também estão incluídos vegetais, como verduras e legumes?

2c) Onde mais podemos encontrar proteínas? Relacione algumas estruturas que constituem seu corpo ou de outros organismos, como algum tipo de tecido ou secreção, que seja constituído basicamente por proteínas.

3a) A grande questão é: Por que precisamos tanto de proteínas? Qual é o grande papel que elas exercem nos organismos?

4) Não resta dúvida de que nosso organismo precisa constantemente suprir suas necessidades de proteínas. Mas como você acha que essas proteínas serão absorvidas pelo nosso organismo? Leve em consideração que os alimentos, antes de serem absorvidos, passam pelo processo de digestão.

6) Você saberia relacionar algumas doenças ou deficiências, de que já tenha ouvido falar, cuja causa está relacionada a alguma proteína específica? Não precisa escrever o nome da proteína, somente a doença.

\section{Resultados e discussão}

As respostas dadas às seis questões estudadas são apresentadas nos Gráficos 1 a 5 , cada um indicando a porcentagem de frequência das respostas por categoria e respectivas correlações com o número de alunos.

Quando pedidos para definirem uma proteína (Gráfico 1), 42 alunos da PuS (64,6\%) e 31 da $\operatorname{PrS}(45,6 \%)$ apresentaram respostas genéricas do tipo: "é uma substância essencial ao nosso corpo, indispensável para o desenvolvimento do corpo e sua nutrição", "acho que serve para dar energia, essas coisas...", "proteína é uma substância necessária para o bom funcionamento do organismo, além de ter várias outras funções", indicando uma tendência em definir genericamente o papel das proteínas no organismo (humano). Essa tendência aproxima-se do senso comum, de concepções alternativas, e não propriamente de conceitos científicos. A inclusão de termos menos genéricos na definição de proteína, como, por exemplo, molécula, substituindo "substância", poderia ser esperada por parte destes alunos, que já haviam estudado aspectos da estrutura e propriedades desta molécula biológica em seus currículos de Biologia no EM.

O Gráfico 2 mostra uma predominância de categorias referentes a alimentos de origem animal: carnes $(74,4 \%)$, leite $(57,9 \%)$ e ovos $(42,1 \%)$, sobre os de origem vegetal (verduras, legumes e frutas), embora a questão 2 b) ("Nessa lista de alimentos ricos em proteínas também estão incluídos vegetais, como verduras e legumes?") tenha revelado que cerca de $70 \%$ dos alunos acreditam que vegetais sejam constituídos de proteínas. Embora os números da questão 
Algumas concepções de alunos do Ensino Médio ...

Gráfico 1. Categorização das respostas referentes à questão 1b) do questionário diagnóstico, com indicação da frequência de cada categoria (\%)

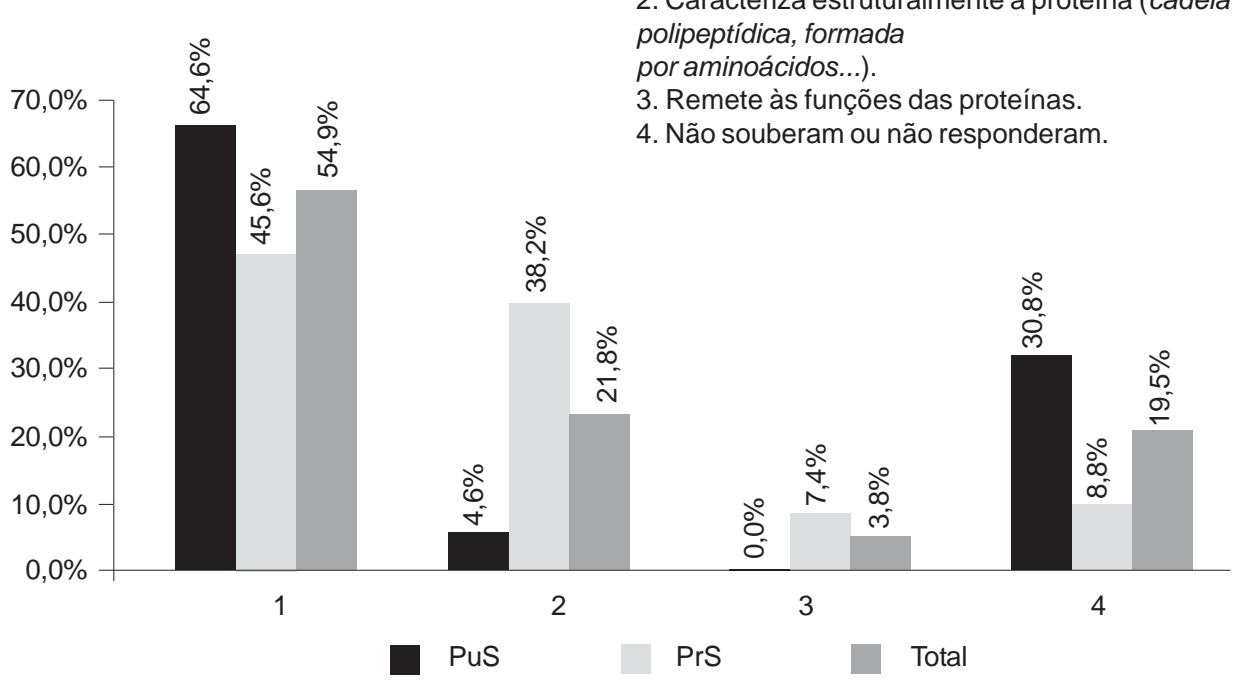

Fonte: Carvalho (2009)

2.b) sejam muito expressivos, a questão 2 a) revela uma tendência dos alunos em associar proteínas aos alimentos de origem animal. Essa tendência pode ser observada, também, nas respostas apresentadas à questão 2c) (Gráfico 3), em que cabelo, músculos e pele foram, em média, os itens mais lembrados como as estruturas corpóreas constituídas de proteínas.

Embora a questão não tenha especificado que se deveriam citar apenas estruturas humanas que fossem constituídas de proteínas, também não se observou nenhuma categoria de resposta que explicitasse a presença de proteínas em vegetais ou em outros organismos vivos, como o exoesqueleto de insetos, por exemplo. Ainda nessa questão, observou-se que um número considerável de alunos $(33,8 \%)$ não a respondeu. Os demais, ao se referirem às estruturas formadas ou compostas por proteínas, mencionaram tecidos e anexos, como cabelo $(21,8 \%)$, músculos $(16,5 \%)$, pele $(15,8 \%)$ ou unha $(11,3 \%)$, percebendo-se uma tendência para entenderem as proteínas apenas como "construtoras" de tecidos, portanto com uma função prioritariamente estrutural. Com isso, a questão 2 indicou certa dificuldade, por parte dos alunos, para relacionar os tipos de proteínas encontradas nos alimentos com os encontrados no corpo humano. Ou seja, apesar de 89 alunos (66,9\%, questão 2b) afirmarem que as proteínas estão presentes também em legumes e verduras, somente em torno de 6 a 28,6\% dos alunos (questão 2a) citaram espontaneamente alimentos de origem vegetal (verduras, legumes, frutas, feijão, cereais, soja e arroz) como fonte de proteínas. A "carne", por exemplo, foi o alimento mais citado como fonte de proteínas (74,4\%, questão $\mathbf{2 a}$ ); em contra- 
Carvalho, J. C. Q.; Couto, S. G.; Bossolan, N. R. S.

Gráfico 2. Categorização das respostas referentes à questão 2a) do questionário diagnóstico, com indicação da frequência de cada categoria (\%)

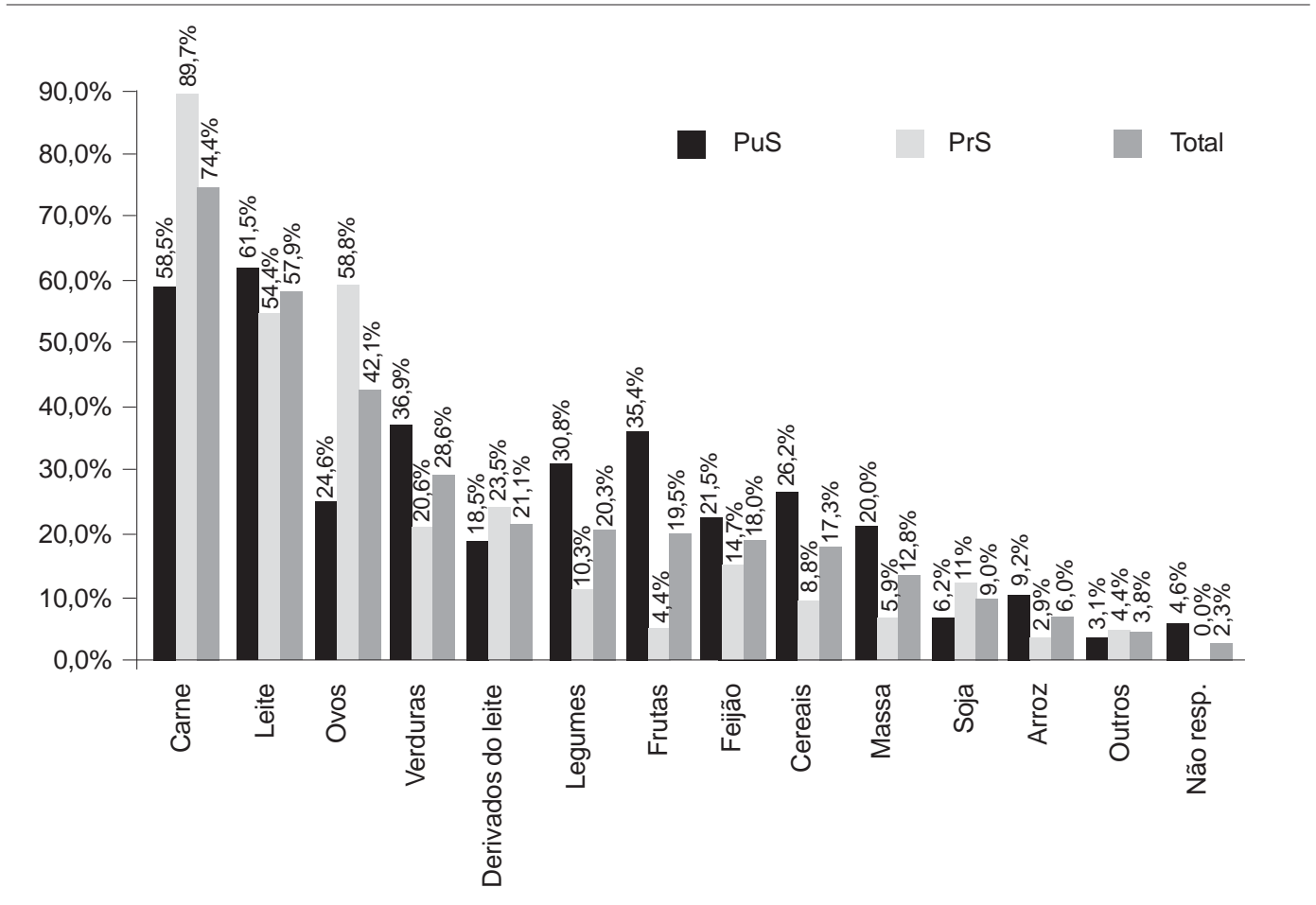

Fonte: Carvalho (2009).

Gráfico 3. Categorização das respostas referentes à questão 2c) do questionário diagnóstico, com indicação da frequência de cada categoria (\%)

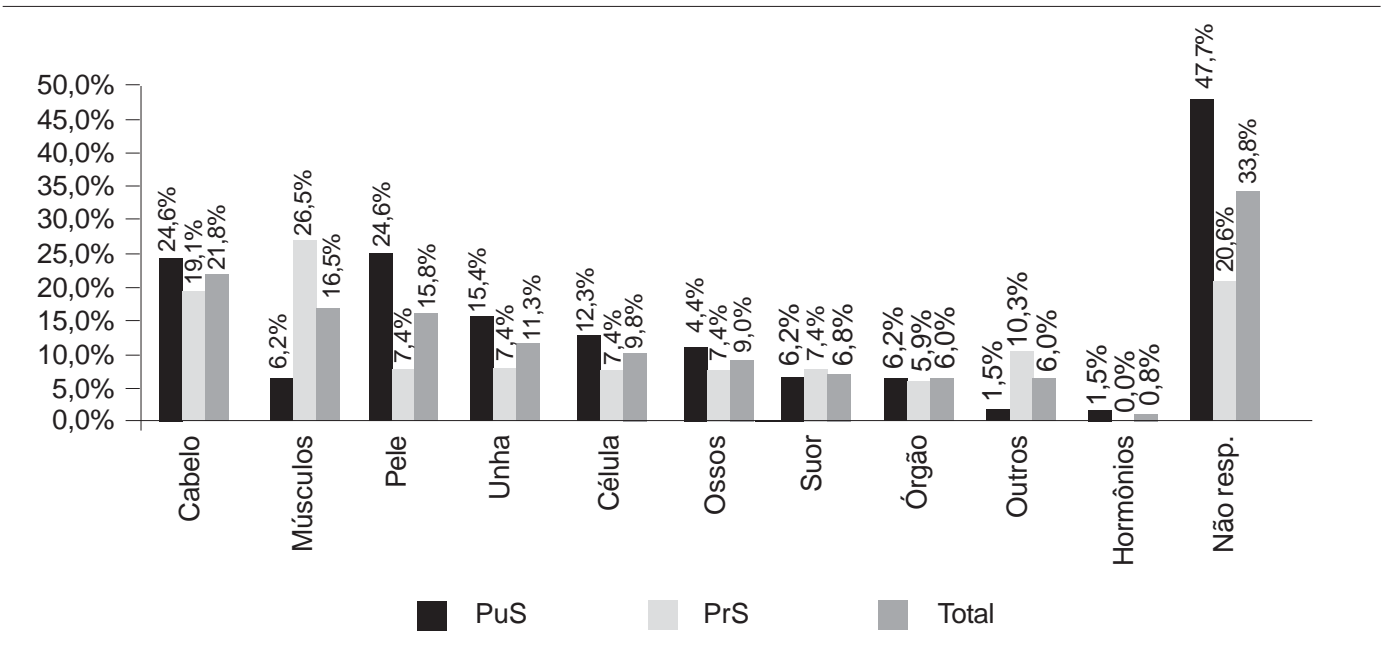

Fonte: Carvalho (2009).

906

Ciência \&̊ Educação, v. 18, n. 4, p. 897-912, 2012 
Algumas concepções de alunos do Ensino Médio ...

partida, na questão 2c, "músculo" foi citado espontaneamente, por apenas 16,5\% dos alunos, como constituinte estrutural de organismos.

Percebemos, pelas categorias de respostas apresentadas no Gráfico 4, que a tendência apresentada pelos alunos, para a questão $\mathbf{1 b}$ (de definir genericamente o papel das proteínas no organismo humano), de certo modo, foi confirmada pelas respostas dadas à questão 3a), quando $55,6 \%$ dos alunos relacionaram proteínas ao caráter mantenedor do organismo, como observado nos trechos: "não se consegue viver bem sem a função que ela exerce no organismo", "porque sem elas nosso corpo não constitui energias para manter nosso corpo saudável", "precisamos de proteínas para que nosso organismo funcione melhor" ou "porque através delas nos mantemos vivos". Do mesmo modo que para a questão 1b), poderia se esperar, nas respostas dadas, uma indicação mais precisa a respeito do papel das proteínas nos organismos, como, por exemplo, a função catalisadora das enzimas.

Gráfico 4. Categorização das respostas referentes à questão 3.a) do questionário diagnóstico, com indicação da frequência de cada categoria (\%).

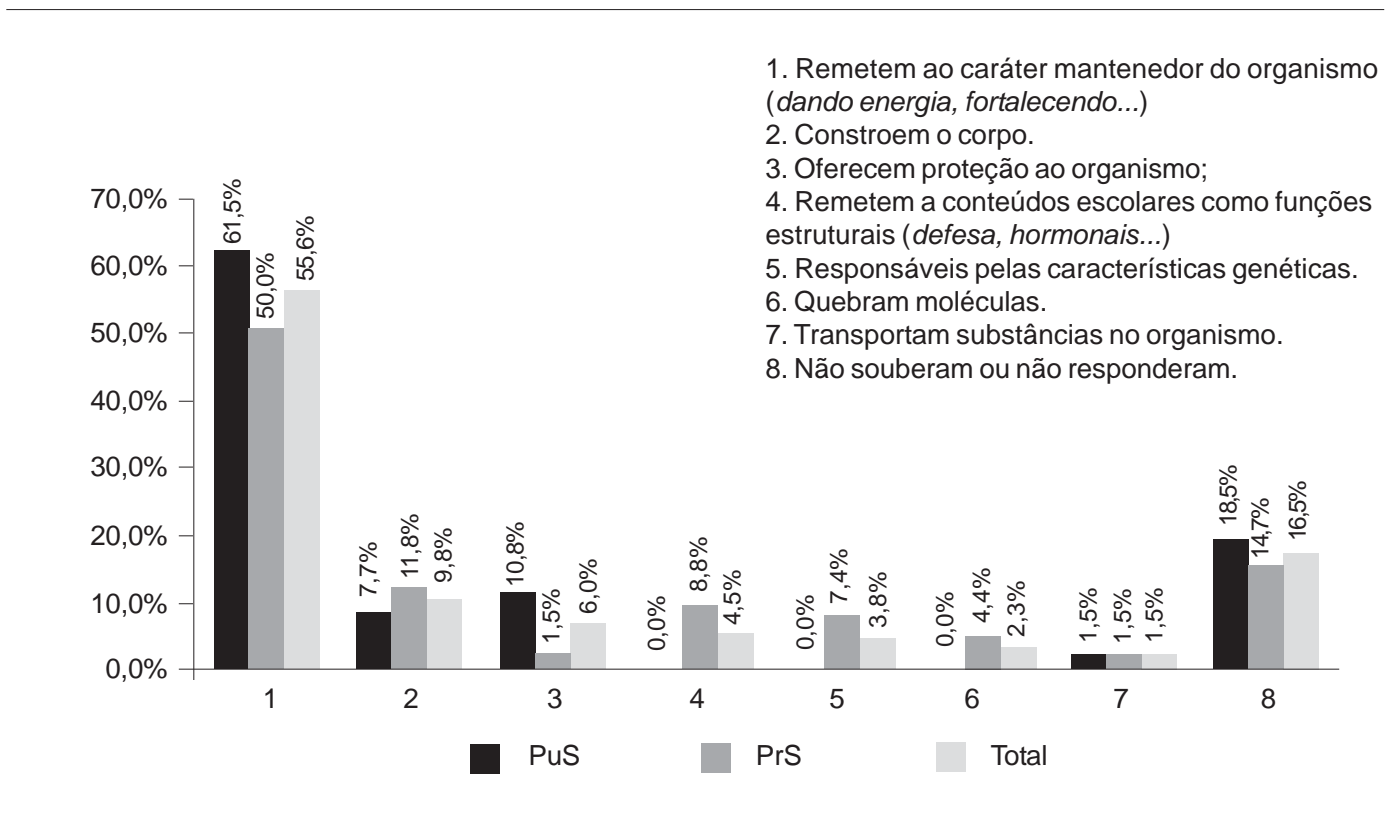

Fonte: Carvalho (2009).

Ao observarmos, no Gráfico 5, as categorias de respostas dadas à questão 4, que pergunta sobre como as proteínas são absorvidas pelo próprio organismo, vimos que grande parte dos alunos pode ter tido uma compreensão falha do processo de digestão, uma vez que $55(41,4 \%)$ não responderam a essa questão, dos quais 38 pertenciam à escola pública. Dos 49 alunos $(36,8 \%)$ que mencionaram a "quebra" das proteínas antes de serem absorvidas pelo organismo, 38 eram da escola particular. As professoras responsáveis pelas turmas informaram que o conteúdo relativo ao processo de digestão humana é tratado no terceiro ano do 
Gráfico 5. Categorização das respostas referentes à questão 4 do questionário diagnóstico, com indicação da frequência de cada categoria (\%).

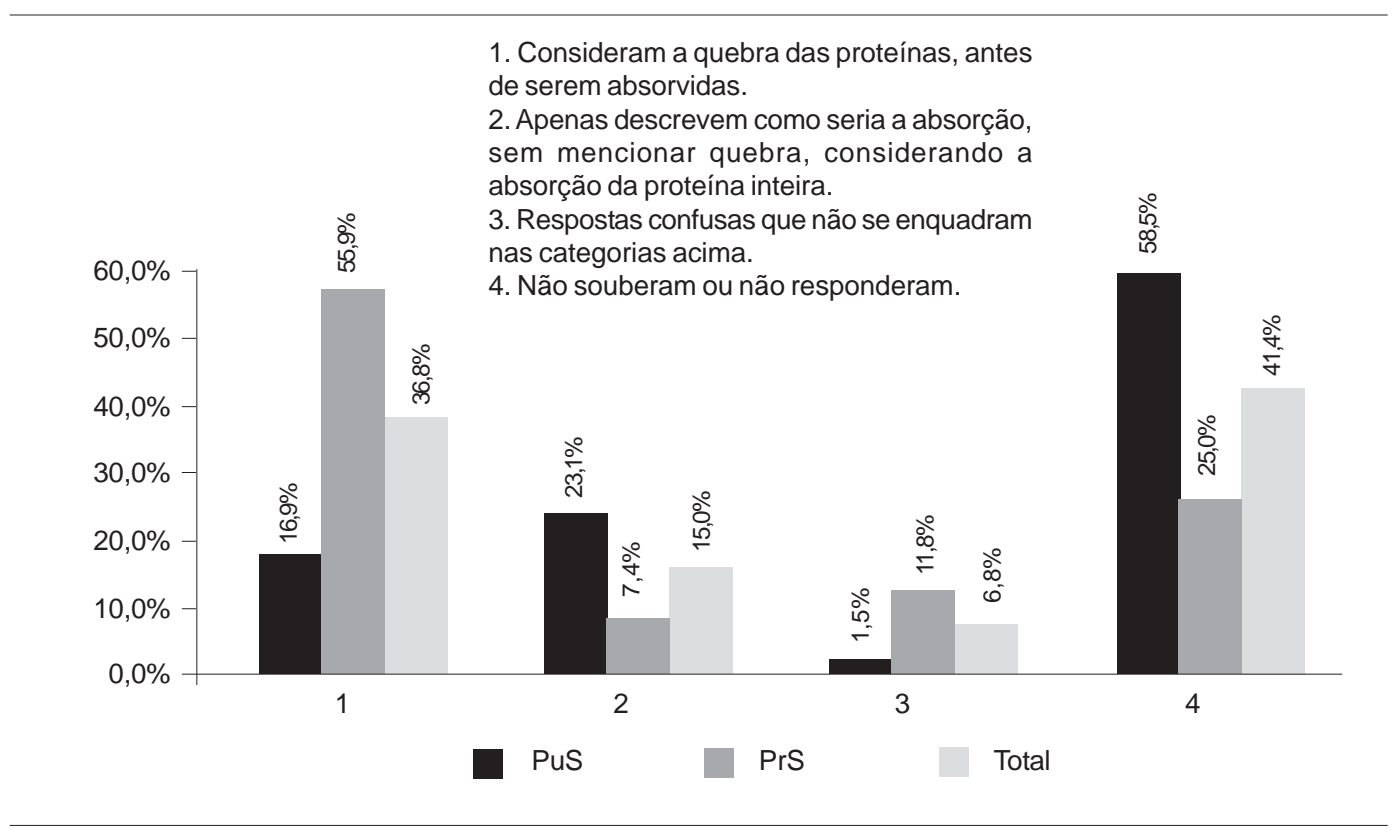

Fonte: Carvalho (2009).

Ensino Médio, ainda que esse conteúdo, de modo menos aprofundado, também seja parte do currículo de Ciências do Ensino Fundamental.

Quanto à associação de algumas doenças/deficiências relacionadas às proteínas (questão 6 - Tabela 1), também percebemos um número considerável de alunos que não respondeu ou não sabia $(49,6 \%)$, dificultando o apontamento de uma tendência, mesmo porque as doenças listadas são bastante diferentes entre si. Entretanto podemos destacar o alto índice de citações de "anemia" (34,6\%), ainda que não seja possível assumir se os alunos estabelecem, nesse caso, uma relação direta da doença com a hemoglobina. Doenças associadas à falta de proteínas específicas, como diabete e albinismo, também foram lembradas por 11,3\% e 10,5\% dos alunos que, neste caso, eram todos da PrS. Citações de doenças como osteoporose, "atrofiamento" muscular, doenças da pele, podem ter sido feitas por conta da associação da presença de proteínas em tecidos como o ósseo, muscular e da pele, conforme resultados observados na questão $2 \mathbf{c}$ ).

Pudemos perceber, dessa forma, que, mesmo já tendo estudado os conceitos de proteínas no ano escolar anterior, os alunos ainda carregam traços de concepções alternativas, o que confirma uma das características dessas concepções, previstas por Pozo (1987 apud GARCIA-MILÀ, 2004), a de "ser resistente a mudanças". Mas também temos de levar em consideração o fato de que a aplicação do questionário diagnóstico tenha sido uma situação diferente de uma prova formal em que os alunos seriam avaliados, podendo ocorrer, segundo Mortimer (1995), a escolha, por parte do aluno, do perfil conceitual que the seria conveniente. Se o 
Algumas concepções de alunos do Ensino Médio ...

Tabela 1. Categorização das respostas referentes à questão 6 do questionário diagnóstico, com indicação da frequência de respostas em cada categoria

\begin{tabular}{|c|c|c|c|c|c|c|}
\hline \multicolumn{7}{|c|}{ Questão 6} \\
\hline Categorias de respostas & \multicolumn{2}{|c|}{ Pus } & \multicolumn{2}{|c|}{ PrS } & \multicolumn{2}{|c|}{ Total } \\
\hline 1. Anemia & 10 & $(15,4 \%)$ & 36 & $(52,9 \%)$ & 46 & $(34,6 \%)$ \\
\hline 2. Osteoporose & 3 & $(4,6 \%)$ & 15 & $(22,1 \%)$ & 18 & $(13,5 \%)$ \\
\hline 3. Diabete & 0 & $(0,0 \%)$ & 15 & $(22,1 \%)$ & 15 & $(11,3 \%)$ \\
\hline 4. Albinismo & 0 & $(0,0 \%)$ & 14 & $(20,6 \%)$ & 14 & $(10,5 \%)$ \\
\hline $\begin{array}{l}\text { 5. Mal-estar (cansaço, sonolência, indisposição, } \\
\text { preguiça, câimbra) }\end{array}$ & 2 & $(3,1 \%)$ & 7 & $(10,3 \%)$ & 9 & $(6,8 \%)$ \\
\hline 6. Cegueira noturna & 0 & $(0,0 \%)$ & 9 & $(13,2 \%)$ & 9 & $(6,8 \%)$ \\
\hline 7. Raquitismo & 1 & $(1,5 \%)$ & 6 & $(8,8 \%)$ & 7 & $(5,3 \%)$ \\
\hline 8. Mal de Parkinson & 0 & $(0,0 \%)$ & 6 & $(8,8 \%)$ & 6 & $(4,5 \%)$ \\
\hline 9. Prisão de ventre & 0 & $(0,0 \%)$ & 6 & $(8,8 \%)$ & 6 & $(4,5 \%)$ \\
\hline 10. Hipoglicemia & 0 & $(0,0 \%)$ & 4 & $(5,9 \%)$ & 4 & $(3,0 \%)$ \\
\hline 11. Síndrome de Down & 0 & $(0,0 \%)$ & 3 & $(4,4 \%)$ & 3 & $(2,3 \%)$ \\
\hline 12. Dores Ósseas & 0 & $(0,0 \%)$ & 3 & $(4,4 \%)$ & 3 & $(2,3 \%)$ \\
\hline 13. Doenças da pele & 0 & $(0,0 \%)$ & 3 & $(4,4 \%)$ & 3 & $(2,3 \%)$ \\
\hline 14. Fenilcetonúria & 0 & $(0,0 \%)$ & 3 & $(4,4 \%)$ & 3 & $(2,3 \%)$ \\
\hline 15. Hanseníase & 0 & $(0,0 \%)$ & 3 & $(4,4 \%)$ & 3 & $(2,3 \%)$ \\
\hline 16. Alergia (leite) & 0 & $(0,0 \%)$ & 3 & $(4,4 \%)$ & 3 & $(2,3 \%)$ \\
\hline 17. Atrofiamento muscular & 1 & $(1,5 \%)$ & 0 & $(0,0 \%)$ & 1 & $(0,8 \%)$ \\
\hline 18. Leucemia & 1 & $(1,5 \%)$ & 0 & $(0,0 \%)$ & 1 & $(0,8 \%)$ \\
\hline 19. Bulimia & 1 & $(1,5 \%)$ & 0 & $(0,0 \%)$ & 1 & $(0,8 \%)$ \\
\hline 20. Desnutrição & 1 & $(1,5 \%)$ & 0 & $(0,0 \%)$ & 1 & $(0,8 \%)$ \\
\hline 21. Gripe & 1 & $(1,5 \%)$ & 0 & $(0,0 \%)$ & 1 & $(0,8 \%)$ \\
\hline 22. Virose & 1 & $(1,5 \%)$ & 0 & $(0,0 \%)$ & 1 & $(0,8 \%)$ \\
\hline Não souberam ou não responderam & 48 & $(73,8 \%)$ & 18 & $(26,5 \%)$ & 66 & $(49,6 \%)$ \\
\hline
\end{tabular}

Fonte: Carvalho (2009).

questionário aplicado tivesse o caráter de uma avaliação formal, talvez os alunos optassem por responder de acordo com o que lhes fora ensinado em sala de aula (definições, nomes, processos, ou seja, conceitos científicos). Numa situação como a da nossa pesquisa, em que os alunos tiveram total liberdade para responder da forma como eles desejassem, as suas concepções alternativas podem ter prevalecido.

O estudo das concepções dos alunos sobre determinado tema se expressa como um diagnóstico do processo de ensino-aprendizagem, um ponto de checagem, fornecendo informações valiosas sobre possíveis falhas nesse processo.

Em especial sobre o tema proteínas, proposto por este trabalho, a superficialidade de algumas das respostas apresentadas pode indicar falhas no processo de ensino e aprendizagem desse tema. Pedrancini et al. (2007), ao estudarem a apropriação do saber científico e biotecnológico entre alunos do Ensino Médio, observaram que os alunos se apropriaram de termos e expressões isoladas muitas vezes estimuladas pela mídia, porém quando são estimulados a explicá-los, percebe-se que não se apropriaram necessariamente dos conceitos científicos envolvidos. Dessa forma, a manutenção de concepções alternativas em temas básicos de biologia, como os exemplos sobre proteínas observados nessa pesquisa, pode dificultar o estabelecimento de conexões futuras com outros assuntos presentes no currículo de biologia do Ensino Médio, como, por exemplo, a genética (relação entre gene, características genéticas e prote- 
ínas), conforme podemos perceber nos trabalhos de Lewis (2000; 2004) e Wood-Robinson, Lewis e Leach (2000), ou, então, nas discussões sobre os avanços da biologia molecular e biotecnologia (PEDRANCINI et al., 2007; BONZANINI; BASTOS, 2005; MARTINEZGRACIA; GIL-QUILEZ, 2003). Devido a essa preocupação, encontramos trabalhos que discutem e propõem possíveis adaptações ao currículo de biologia frente a esses novos temas (FALK; BRILL; YARDEN, 2008; SAEZ; NIÑO; CARRETERO, 2008); e essa preocupação, segundo Venville e Donavan (2007), deve começar, inclusive, no Ensino Básico, devido à grande exposição das crianças, desde cedo, a esses temas por meio da mídia.

Para haver uma possível "ressignificação" e inter-relação entre o tema proteínas e outros, como genética, por exemplo, é necessário que as possibilidades de discussão sejam ampliadas, mostrando, aos alunos, que a "proteína" estudada no capítulo de nutrição é a "mesma" do capítulo de genética. Nesse sentido, Wood-Robinson, Lewis e Leach (2000) constataram que o currículo e os autores de livros didáticos incluem, frequentemente, processos complexos, como "síntese proteica" e "engenharia genética", sem oferecer a devida correlação com os conceitos básicos envolvidos, que devem ser entendidos primeiro.

\section{Agradecimentos}

À profa. dra. Leila Maria Beltramini, professora associada do Instituto de Física da USP de São Carlos (IFSC-USP), coordenadora do setor de Educação e Difusão do Centro de Biotecnologia Molecular Estrutural (CBME/CEPID/FAPESP) e coautora do jogo Sintetizando Proteínas. Às professoras Ana Claudia Toledo dos Santos Prado e Alessandra Fernandes Rosa (Escola Estadual Prof. Álvaro Guião), Adriana do Valle Berganton (Colégio Educativa), e aos seus respectivos alunos do segundo ano do Ensino Médio, por terem colaborado com essa pesquisa. À Capes, ao CNPq e à Fapesp, pelo auxílio financeiro que possibilitou a realização desta pesquisa.

\section{Referências}

ACEVEDO, J. A. et al. Mitos da didática das ciências acerca dos motivos para incluir a natureza da ciência no ensino de ciências. Ciência \& Educação, Bauru, v. 11, n. 1, p. 1-15, 2005.

BOGDAN, R.; BIKLEN, S. Investigação qualitativa em educação: uma introdução à teoria e aos métodos. Porto: Porto Editora, 1994.

BONZANINI, T. K.; BASTOS, F. Concepções de alunos do ensino médio sobre clonagem, organismos transgênicos e projeto genoma. In: ENCONTRO NACIONAL DE PESQUISA EM EDUCAÇÃO EM CIÊNCIAS, 5., 2005, Bauru. Atas... Bauru: ABRAPEC, 2005. 1 CD-ROM. 
Algumas concepções de alunos do Ensino Médio ...

BRASIL. Ministério da Educação. Parâmetros curriculares nacionais - ensino médio: parte 3, ciências da natureza, matemática e suas tecnologias. Brasília, DF, 1999.

Ministério da Educação. PCN+ ensino médio: orientações educacionais complementares aos parâmetros curriculares nacionais - ciências da natureza, matemática e suas tecnologias. Brasília, DF, 2002.

CACHAPUZ, A. et al. A necessária renovação do ensino das ciências. São Paulo: Cortez, 2005.

CARVALHO, J. C. Q. Avaliação do impacto do jogo "Sintetizando Proteínas" no processo de ensino-aprendizagem de alunos do ensino médio. 2009. $230 \mathrm{f}$.

Dissertação (Mestrado em Física Aplicada) - Instituto de Física, Universidade de São Paulo, São Carlos, 2009.

FALK, H.; BRILL, G.; YARDEN, A. Teaching a biotechnology curriculum based on adapted primary literature. International Journal of Science Education, London, v. 1, n. 1, p. 1-26, 2008.

GARCIA-MILÀ, M. O ensino e a aprendizagem das ciências físico-naturais: uma perspectiva psicológica. In: COLL, C.; ÁLVARO, M.; PALACIOS, J. (Org.).

Desenvolvimento psicológico e educação: psicologia da educação escolar. 2. ed. Porto Alegre: Artmed, 2004. p. 361-363.

GIL, A. C. Métodos e técnicas de pesquisa social. 5. ed. São Paulo: Atlas, 1999.

GILBERT, W. Rumo ao proteoma. Ciência Hoje, São Paulo, v. 29, n. 173, p. 8-11, 2001.

HAYDT, R. C. Avaliação do processo ensino-aprendizagem. 4. ed. São Paulo: Ática, 1994.

LEWIS, J. Traits, genes, particles and information: re-visiting students' understandings of genetics. International Journal of Science Education, London, v. 26, n. 2, p. 195-206, 2004.

LEWIS, J.; LEACH, J.; WOOD-ROBINSON, C. All in the genes? young people's understanding of the nature of genes. Journal of Biological Education, New York, v. 34, n. 2, p. 74-79, 2000.

LÜDKE, M.; ANDRÉ, M. E. D. A. Pesquisa em educação: abordagens qualitativas. São Paulo: EPU, 1986.

MARTÍNEZ-GRACIA, M. V. ; GIL-QUÍLEZ, M. J. Genetic engineering: a matter that requires further refinement in Spanish secondary school textbooks. International Journal of Science Education, London, v. 25, n. 9, p. 1147-1168, 2003.

MORTIMER, E. F. Conceptual change or conceptual profile change? Science $\boldsymbol{\&}$ Education, Dordrecht, v. 4, n. 3, p. 267-285, 1995.

PEDRANCINI, V. D. et al. Ensino e aprendizagem de biologia no ensino médio e a apropriação do saber científico e biotecnológico. Revista Electrónica de Enseñanza de las Ciências, v. 6, n. 2, p. 299-309, 2007. 
Carvalho, J. C. Q.; Couto, S. G.; Bossolan, N. R. S.

POZO, J. I. A aprendizagem e o ensino de fatos e conceitos. In: COLL, C. et al. Os conteúdos na reforma. Porto Alegre: Artes Médicas, 1998. p. 17-71.

SÁEZ, M. J.; NIÑO, A. G.; CARRETERO, A. Matching society salues: students' views of biotechnology. International Journal of Science Education, London, v. 30, n. 2, p. $167-183,2008$.

SANTOS, W. L. P.; SCHNETZLER, R. P. Educação em química: compromisso com a cidadania. Ijuí: Ed. Unijuí, 2000.

VENVILLE, G.; DONOVAN, J. Developing year 2 students' theory of biology with concepts of the gene and DNA. International Journal of Science Education, London, v. 29, n. 9, p. 1111-1131, 2007.

VYGOTSKY, L. S. Pensamento e linguagem. São Paulo: Martins Fontes, 1991.

WOOD-ROBINSON, C.; LEWIS, J.; LEACH, J. Young people's understanding of the nature of genetic information in the cells of an organism. Journal of Biological

Education, New York, v. 35, n. 1, p. 29-36, 2000.

ZEIDLER, D. L. et al. Tangled up in views: beliefs in the nature of science and responses to socioscientific dilemmas. Science Education, Salem, v. 86, n. 3, p. 343-367, 2002.

Artigo recebido em 30/12/2011. Aceito em 18/07/2012. 